\title{
ASPECTOS DA SUBORDINAÇÃO NO DIREITO DO TRABALHO. Suas implicações no contexto das novas tecnologias da comunicação e da informação.
}

\author{
THE FACES OF SUBORDINATION IN LABOR LAW. Its \\ implications in the context of the new communications and \\ information's technologies.
}

Recebimento em 23/09/2015

Aceito em 22/09/2017

\author{
Everaldo Gaspar Andrade ${ }^{1}$ \\ Zelia Costa Santos Bezerra ${ }^{2}$
}

\begin{abstract}
RESUMO
A doutrina clássica aponta o trabalho livre-subordinado como objeto do Direito do Trabalho. Por isso, o tema subordinação, conecta-se com o Poder Diretivo ou Disciplinar do empregador. A partir da Revolução Tecnológica empreendida nos últimos anos, aliada à inserção das novas tecnologias da informação e da comunicação no mundo do trabalho, essa mesma doutrina clássica vem apresentando, como modo de enfrentamento da crise da subordinação, os conceitos de parassubordinação e de flexisseguração. Os autores deste artigo entendem, primeiro, que o tema não será convenientemente desvendado sem se articular estas duas propostas àquelas que vêm sendo apresentadas pela teoria organizacional conservadora - a empregabilidade e o empreendedorismo. Reforça as suas convicções na ideia de que a inserção das novas tecnologias e o aparecimento dos infoproletários desencadearam um controle maior sobre o trabalho e uma ampliação na jornada a ser cumprida e, por consequência, os rituais do sofrimento. Ideologicamente, houve uma autorrealização imposta, quando se passou a cooptar a autonomia e impor novas formas de opressão no interior das organizações.
\end{abstract}

Palavras-cheve: subordinação, parassubordinação, empregabilidade, empreendedorismo, infoproletários, tecnologia da comunicação e da informação.

\begin{abstract}
The classical doctrine maintains free/subordinated labor as the central object of labor low. This is why the study of subordination is connected with Directive or Disciplinary power of the employer. From the Technological Revolution that has been happening in the last few years, allied with the introduction of new technologies in the worker's world, the classical doctrine is introducing, as a way of facing the subordination crisis, the concepts of labor that goes beyond subordination (parasubordinação), which it is characterized by the idea of coordination, and of flexicurity. The authors of this article understand that the theme is not conveniently unveiled without articulating this two proposals with those that have been shown by the conservative organization theory - employability and entrepreneurship. The authors reinforce their convictions in the idea that the insert of new technologies and the appearance of info workers caused a major control of work and excessive working hours and therefore the rituals of suffering. Ideologically, there were a self-realization imposed by the cooption of autonomy and the imposition of new ways of oppression inside of the organizations.
\end{abstract}

Keywords: Subordination, employability, entrepreneurship, info workers, information and communications technology.

\footnotetext{
${ }^{1}$ Doutor em Direito pela Universidade de Deusto. Professor da Faculdade de Direito do Recife/CCJ/UFPE.

${ }^{2}$ Mestra em Direito pela PPGD/UFPE.
} 


\section{INTRODUÇÃO}

Este artigo tem como objetivo demonstrar as implicações da Revolução Informacional no instituto da subordinação.

Deixará transparecer, de início, que as relações de trabalho subordinadas, como objeto do Direito do Trabalho, não aparecem como um fenômeno transhistórico, mas datado. Aparece com o advento do Estado Moderno que, em nome do falso pressuposto liberdade/igualdade, instituiu o discurso de libertação - do trabalho escravo e servil -, por meio do trabalho contraditoriamente livre/subordinado - enquanto lócus privilegiado da sociabilidade e a priori das teorizações, no campo da sociologia clássica e deste campo do conhecimento jurídico.

Surge na medida em que a burguesia não veio para ser hegemônica num país ou região, mas, no mundo; porque, para ser hegemônica, neste mesmo âmbito espacial, precisaria criar um direito dogmaticamente organizado - fruto de argumentos muito bem forjados, por meio da aliança entre filósofos e juristas. O primeiro, para formular uma ética omnicompreensiva - no caso do Direito do Trabalho, para instituir a glorificação/evangelização do trabalho livre/subordinado como protoforma da vida -; o segundo, para formular os fundamentos de uma teoria geral para este ramo do direito centrado naquele objeto.

O Estado Moderno, respaldado na filosofia liberal - posta a serviço do racionalismo instrumental típico do Modo de Produção Capitalista - passou a legitimar a subordinação da força do trabalho ao capital. Logo, um tipo de relação de trabalho centrada numa relação de poder.

Este artigo demonstrará ainda que não há como eliminar o adoecimento e a subordinação enquanto a sociedade do trabalho estiver condicionada a um modelo jurídico-estatal que universaliza e legitima o Modo de Produção Capitalista, porque é exatamente ele que subordina a força de trabalho ao capital.

Por fim, deixará transparecer que a Revolução Tecnológica ou Informacional aumentou os mecanismos de controle e de subordinação, ao instituir mecanismos organizacionais ainda mais sofisticados, em dois sentidos: a) agora, ao contrário do chão 
da fábrica de raiz fordista/taylorista, o empregado pode ser controlado a todo minuto, em todas as horas do dia, da semana, do mês e do ano; pode ser controlado dentro e fora das organizações e onde quer que esteja; b) os novos métodos de gestão e de administração, no modelo de Acumulação Flexível, são capazes de capturar não só os braços do operário, mas a sua subjetividade e a sua alma.

\section{A REVOLUÇÃO INFORMACIONAL E SEU IMPACTO NO INSTITUTO DA SUBORDINAÇÃO}

O tema envolve aquilo que os teóricos da pós-modernidade ou do marxismo não ortodoxo costumam chamar de Capitalismo Cognitivo - na expressão utilizada por COCCO, GALVÃO E SILVA (2003) ${ }^{3}$-, ou de Revolução Informacional, trazida por LOJKINE (2002) ${ }^{4}$ e prossegue no questionamento formulado por Sérgio Lessa - um marxista ortodoxo.

Para este último, os defensores do chamado "trabalho imaterial” se envolvem não somente com a defesa de uma nova forma de produção e uma nova concepção de história centrada no "amor ao tempo", que conduziria naturalmente a um modo diferente de produção. Uma transição do capitalismo para o comunismo que resultaria de um estilo de vida distinto - o comunista -, mas que não significaria a superação do capital, do mercado, do dinheiro e do Estado. Sérgio Lessa discorda e combate esta posição, por entender que não é possível, por este viés, superar os antagonismos decorrentes da subordinação da força do trabalho ao capital, posto que, para tanto, deveriam acontecer lutas emancipatórias advindas desse antagonismo e protagonizadas pela classe operária. ${ }^{5}$

Embora reconheça este dilema entre teorias tão diferentes, não podemos deixar de compreender como se movem as relações de trabalho exercitadas pelos profissionais que lidam com a tecnologia da informação e da comunicação - tanto aqueles que apenas se

${ }^{3} \mathrm{COCCO}$, Giuseppe; GALVÃO, Alexander Patez; SILVA, Geraldo (orgs.) Capitalismo cognitivo: trabalho, redes e inovação. Rio de Janeiro: DP\&A, 2003.

${ }^{4}$ LOJKINE, Jean. Revolução Informacional. 3.ed. Cortez Editora: São Paulo, 2002.

${ }^{5}$ LESSA, Sérgio. Para Além do Capital? Crítica da teoria do trabalho imaterial. São Paulo: Xamã, 2005., 
utilizam dessas tecnologias, como meros instrumentos de trabalho; como aqueles que produzem e criam as alternativas tecnológicas para o exercício desse trabalho ou os que exercitam, ao mesmo tempo, a criação e a reprodução desses mecanismos. Essa mistura foi notada por Juan José Castillo, quando afirma:

Michael Cussomano,(...), começa por destacar que produzir software não é igual a qualquer outro negócio, como a fabricação de muitos outros bens ou serviços. Porque uma vez criado, o custo é o mesmo tanto para fazer uma cópia quanto para um milhão. Porque se trata de um tipo de empresa cujo lucro sobre as vendas podem chegar a 99\%. Porque é um negócio que pode passar, de uma hora para outra, da fabricação de produtos à prestação de serviços. (...) $\mathrm{O}$ desenvolvimento de software pode ser de produtos padronizados, personalizados e únicos para uma empresa, de serviço à distância, etc. A variabilidade e a diferença de complexidade, sob o mesmo rótulo é constrangedora. Não há apenas um produto software, mas múltiplos e variados. Basta acessar as páginas na internet das muitas empresas que temos consultado para observar produtos dedicados a um mercado restrito e com aparência de ser um produto "empacotado", padronizado, que pode ser dirigido quase exclusivamente a um mercado restrito, a um coletivo profissional, a um tipo de recorte orientado por um computador, a uma gestão de pessoal específica. Isso resultará em complexidades e problemas para a pesquisa muitos distintos no que diz respeito ao momento de construir um coletivo de trabalhadores, analistas, programadores, chefes de aplicações etc. de possíveis "fábricas de software". Mesmo Cusumano, um autor de referência e solidez, denomina a "atividade técnica mais fundamental das empresas de software: o desenvolvimento de software". Muitos pesquisadores têm chamado a atenção para essa riqueza de figuras produtivas de vivências e expectativas de trabalho, sobretudo para as repercussões na vida privada e na organização do tempo com ênfase especial, precisamente, nos produtores de software cujos postos de trabalho se movem entre "a rotina e os postos de nível mais elevado". 6

O fato é que a revolução tecnológica segue resoluta em busca da substituição do trabalho humano pelas máquinas inteligentes, o que já vem ocorrendo, de forma acelerada, em vários setores tradicionais do processo produtivo. Como afirma Adam Shaff,

Trata-se da segunda revolução técnico-industrial. A primeira, que pode ser situada entre o final do século XVIII e o inicio do século XIX e cujas transformações ninguém hesita hoje em chamar de revolução, teve o grande mérito de substituir na produção a força física do homem pela energia das máquinas (primeiro pela utilização do vapor e mais adiante sobretudo pela utilização da eletricidade). A segunda revolução, que estamos assistindo agora, consiste em que as capacidades intelectuais do homem são ampliadas e inclusive substituídas por autômatos, que eliminam com êxito crescente o trabalho humano na produção e nos serviços. ${ }^{7}$

${ }^{6}$ Castillo, Juan José. O Trabalho do conhecimento na sociedade da informação: a análise dos programadores de software in ANTUNES, Ricardo. BRAGA, Ruy (org.). Infoproletários: degradação real do trabalho virtual. São Paulo: Boitempo, 2009. P. 22 e 23

${ }^{7}$ SHAFF, Adam. A sociedade informática: as consequências sociais da segunda revolução industrial. 4. Ed. São Paulo: Editora da Universidade Estadual Paulista: brasiliense, 1995. P. 22 
No entanto, por mais sofisticadas que sejam as relações de trabalho, neste âmbito, o elemento subordinação, em vez de ter sido eliminado, foi ainda mais ampliado. Antes, no Chão da Fábrica - típico da forma gerencialista ditada pelo Fordismo/Taylorismo de gestão e de administração - o Poder Diretivo ou Disciplinar do empregador - com sua capacidade de admitir, assalariar e dirigir a prestação pessoal de serviços - limitava-se ao interior das organizações produtivas - chefes e comandos pessoas. A passagem do modelo Fordista/Taylorista para o modelo de Administração Flexível, ampliado por meio da inserção das novas tecnologias, foi capaz redimensionar o poder disciplinar/punitivo e sofisticar as possibilidades de subordinação da força do trabalho ao capital.

Os autores deste trabalho, nos capítulos posteriores, tratarão da SUPREMACIA DO TRABALHO LIVRE/SUBORDINADO COMO OBJETO DO DIREITO DO TRABALHO, a fim de apontar os seus dilemas e suas contradições. Para tanto, irão abordar o trabalho livre/subordinado como objeto do Direito do Trabalho na versão da doutrina jurídico-trabalhista clássica. Em seguida, descreverão a reviravolta analítica, ou seja: a contradição que existe no enunciado: trabalho ao mesmo tempo livre e subordinado.

O Terceiro Capítulo analisará o EMBARALHAMENTO CATEGORIAL SOBRE SUBORDINAÇÃO. AS TECNOLOGIAS DA INFORMAÇÃO E DA COMUNICAÇÃO E AS NOVAS FORMAS DE GESTÃO TRAZIDAS PELA TEORIA ORGANIZACIONAL CONSERVADORA. Neste contexto, põem em relevo os temas parassubordinação e flexissegurança, empregabilidade e empreendedorismo apontados pela teoria jurídico-trabalhista tradicional e a teoria organizacional conservadora como alternativas para contornar os dilemas que envolvem a subordinação nas relações individuais de trabalho. ${ }^{8}$

O Quarto Capítulo empreende uma análise sobre "AS ALÇAS DA COOPTAÇÃO” E OS “NOVOS DISPOSITIVOS DE OPRESSÃO”, NO CENÁRIO DO NOVO ESPÍRITO DO CAPITALISMO, segundo a visão de BOLTANSKI E CHAPELLO. O Quinto Capítulo descreve OS EFEITOS DA RECONFIGURAÇÃO DO PODER DIRETIVO E DA SUBORDINAÇÃO, NO ÂMBIDO DOS

\footnotetext{
${ }^{8}$ Tema desenvolvido criticamente no livro: D’ÂNGELO, Isabele Bandeira de Moraes. A Subordinação no Direito do Trabalho. Para ampliar os cânones da proteção, a partir da Economia Social e Solidária. São Paulo: LTr, 2014.
} 
TRABALHADORES DA TECONOLGIA DA INFORMAÇÃO E DA CUMUNICAÇÃO.

\section{A SUPREMACIA DO TRABALHO LIVRE/SUBORDINADO COMO OBJETO DO DIREITO DO TRABALHO. DILEMAS E CONTRADIÇÔES.}

O Direito do Trabalho passou a constituir-se como ramo autônomo do conhecimento jurídico quando foi capaz de eleger o seu objeto, ou seja, o trabalho contraditoriamente livre/subordinado.

Esta a razão pela qual, dentre os pressupostos caracterizadores do contrato individual de trabalho e para distinguir a relação de emprego das demais relações contratuais de natureza civil e comercial, aparecer a subordinação como elemento por intermédio do qual se pode respaldar a existência de um poder de comando ou disciplinar do empregador.

$\mathrm{Na}$ experiência legislativa brasileira, a partir da junção dos artigos $2^{\circ}$. e $3^{\circ}$. da CLT, encontra-se, de um lado, o empregador que admite, assalaria, dirige a prestação pessoa de serviços e detém o Poder Disciplinar; do outro, o empregado, que fica jurídica, econômica e psicologicamente subordinado ao empregador.

Acontece que, da constituição deste modelo de sociedade - centrada no trabalho livre/subordinado - à sua consolidação - na Era Fordista - e, também, nos períodos que a sucederam, a subordinação jurídica ou hierárquica, o poder disciplinar ou de comando patronal se instituía e era experimentado num determinado espaço físico - o "chão da fábrica" ou o estabelecimento empresarial. De dependia ou era condicionado, para sua efetivação, às ordens ou comandos expressos materializados por iniciativas diretas do empregador ou de seus prepostos. 
Logo, o Poder Punitivo e a Subordinação Jurídica ou Hierárquica adquiriram um status relevante, no âmbito da doutrina clássica e passou a inspirar os mais notáveis juslaboralistas na produção de obras voltadas especificamente para este tema. Obras de qualidade excepcional que passaram a integrar uma bibliografia indispensável para compreensão do próprio Direito do Trabalho clássico. ${ }^{9}$

\subsection{A REVIRAVOLTA ANALÍTICA. A CONTRADIÇÃO DO ENUNCIADO: TRABALHO AO MESMO TEMPO LIVRE E SUBORDINADO.}

Por traz desta versão tradicional sobre a subordinação encontrava-se uma concepção analítica que pode ser traduzida da seguinte maneira: o Direito do Trabalho havia empreendido uma verdadeira revolução, no âmbito do Direito Privado, na medida em que reconfigurou os sentidos do individualismo contratualista, oriundos da filosofia liberal clássica, ou mais precisamente os pressupostos da liberdade e da igualdade entre os sujeitos da relação contratual.

$\mathrm{Na}$ medida em que passou a regular uma relação contratual pautada na assimetria entre os sujeitos - empregador e empregado -, não poderia centrar-se no binômio liberdade/igualdade. Teria, pois, que criar mecanismos teórico/dogmáticos capazes de conceder superioridade jurídica ao empregado - inferior na relação contratual -, para compensar a superioridade jurídico-econômica do empregador e empreende, por este caminho, uma simetria entre aqueles sujeitos. Daí o Princípio da Proteção e seus caracteres de irrenunciabilidade, inderrogabilidade, indisponibilidade e ordem pública resplandecidos, na experiência dogmática brasileira, por meio dos artigos 444, 468 e 9 da CLT.

Para enfrentar esta ambiguidade ${ }^{10}$ aponta-se que, apesar deste pressuposto, a doutrina clássica não consegue superar o seguinte dilema:

O Direito do Trabalho e seus fundamentos desencadearam realmente uma revolução no campo do Direito Privado ou foi ele próprio indispensável para legitimar os modelos de estado e de sociedade que surgiram após a queda do

\footnotetext{
9 Dentre elas: DELGADO, Maurício Godinho. O Poder Empregatício. São Paulo: LTR, 1996; RIVAS, Daniel. La Subordinación. Criterio distintivo del contrato de trabajo. Montevideo: Fundación Cultura Universitária, 1996; ROMITA, Arion Sayão Romita. A Subordinação no Contrato de Trabalho. Rio de Janeiro: Forense, 1979.

${ }^{10}$ ANDRADE, Everaldo Gaspar Lopes de. O Direito do Trabalho na Filosofia e na Teoria Social Crítica. Os sentidos do trabalho subordinado na cultura e no poder das organizações. São Paulo: LTr, 2014.
} 
Absolutismo Monárquico - em que os poderes se encontravam nas mãos do clero de da nobreza -, e permitir a ascensão da burguesia nascente ao poder e dar origem ao Estado Liberal - centrado no individualismo contratualista, na supremacia do trabalho vendido, comprado separado da vida e no racionalismo instrumental a serviço da produção capitalista? (Idem, p. 21).

Entende-se assim que a doutrina tradicional e majoritária não é capaz de superar uma contradição que aparece no centro de seus próprios argumentos, ou seja:

\begin{abstract}
Como eliminar a assimetria, a desigualdade entre aqueles dois sujeitos empregador e empregado -, quando de um lado, encontra-se aquele que admite, assalaria, dirige e disciplina a prestação pessoal de serviços - o empregador e, do outro, aquele que fica jurídica, econômica e psicologicamente subordinado ao empregador - o empregado -? Como eliminá-la se, em virtude dessa desigualdade, aparece uma coação - jurídica, econômica e psicológica subjacente e que existe em potência? É no centro deste mesmo argumento que se pode identificar também uma aporia: trabalho livre e, ao mesmo tempo, subordinado. (Idem, p. 21).
\end{abstract}

Admite a professora Isabele de Moraes D’Angelo (2014) que,

Se o trabalho subordinado não é mais hegemônico e apareceram infinitas modalidades ou alternativas de trabalho e rendas que convivem com a subproletarização e o desemprego estrutural, faz-se necessário, inicialmente, descaracterizar a ideologia que o glorificou e deu-lhe uma característica que ele jamais poderia ter - a de trabalho livre -, para que se possa atribuir-lhe outro sentido. Este é o espaço privilegiado da filosofia, para construir o seu aspecto ontológico e rejeitar o seu aspecto meramente mercantilista. (Idem, p. 68).

Depois de estabelecer um percurso que vai desde a sociologia clássica - Marx, Weber e Durkheim - lembra Foucault, para admitir que o poder punitivo que justifica e legitima as relações individuais de trabalho é o mesmo que se estabelece para reger a sociedade como um todo.

Filia-se à nova corrente do pensamento jurídico-trabalhista crítico, que procura problematizar e refutar o próprio trabalho subordinado como objeto do Direito do Trabalho. Alguns adeptos desta nova corrente, tal como ela própria, põem em relevo o trabalho livre e a Economia Social ou Solidária, como variáveis que deveriam substituir aquele objeto tradicional deste ramo do direito. ${ }^{11}$

11 Ver: ANDRADE, Everaldo Gaspar Lopes de Andrade. Direito do Trabalho e Pós-modernidade. Fundamentos para uma teoria geral. São Paulo: LTR, 2005; MELHADO, Reginaldo. Poder e Sujeição. Os fundamentos da relação de poder entre capital e trabalho e o conceito de subordinação. São Paulo: LTR, 2003. COUTINHO, Aldacy Rachid. O Poder Punitivo Trabalhista. São Paulo: LTr, 1999. 


\section{O EMBARALHAMENTO CATEGORIAL SOBRE SUBORDINAÇÃO. AS TECNOLOGIAS DA INFORMAÇÃO E DA COMUNICAÇÃO E AS NOVAS FORMAS DE GESTÃO TRAZIDAS PELA TEORIA ORGANIZACIONAL CONSERVADORA.}

\subsection{A PARASSUBORDINAÇÃO E FLEXISSEGURANÇA, EMPREGABILIDADE E EMPREENDEDORISMO COMO ALTERNATIVAS PARA CONTORNAR OS DILEMAS QUE ENVOLVEM A SUBORDINAÇÃO NAS RELAÇÕES INDIVIDUAIS DE TRABALHO.}

Com o advento revolução tecnológica - ou da tecnologia da informação e da comunicação, que seguiu os passos da Revolução Industrial, até chegar à robótica, à telemática às maquinas inteligentes ${ }^{12}$ - houve uma reviravolta analítica sobre os temas subordinação, poder disciplinar ou diretivo da empresa, em dois sentidos: a) o aparecimento avassalador da relação triangular - a terceirização -, que passou a afetar, dentro e fora do chão da fábrica, a responsabilidade trabalhista voltada, antes, para um único empregador b; o envolvimento da subordinação com uma certa ambiguidade, no que confere ao aparecimento, para alguns autores, de uma certa linha cinzenta - entre liberdade e dependência.

Não era novidade para Marx e Engels, já nos idos de 1848, que a "grande indústria criou o mercado mundial, preparado pela descoberta da América. O mercado Mundial expandiu prodigiosamente o comércio, a navegação e as comunicações” (Idem, p. 6). Também não foi por acaso que a burguesia despojou "de sua aura todas as atividades até então consideradas com respeito e temor religioso. Transformou o médico, o jurista, o padre, o poeta, o homem de ciência, em assalariados por ele remunerados" (Idem,. P. 28).

\footnotetext{
${ }^{12}$ A propósito, Marx e Engels também já haviam prognosticado no Manifesto, que a "burguesia não pode existir sem revolucionar permanentemente os instrumentos de produção; portanto, as relações de produção; e assim, o conjunto das relações sociais... Pela exploração do mercado mundial, a burguesia ornou cosmopolita a produção e o consumo de todos os países... Em apenas um século de sua dominação de classe, a burguesia criou forças de produção mais imponentes e mais colossais que todas as gerações precedentes reunidas. $\mathrm{O}$ domínio das forças naturais, o maquinismo, as aplicações da química à industria e à agricultura, a navegação a vapor, as ferrovias, o telégrafo, o desbravamento de continentes inteiros, a canalização dos rios, o aparecimento súbito de populações - em que século anterior se poderia prever que tais forças produtivas cochilavam no seio do trabalho social? MARX, K.; ENGELS, F. Manifesto do Partido Comunista - 1848. Porto Alegre: L\&M, 2012, pp. 28-32. E mais:
} 
Logo, a doutrina jurídico-trabalhista clássica, além de não ter superado a contradição que envolve o seu próprio objeto - trabalho contraditoriamente livre/subordinado -, não se sustenta por meio do binômio parassubordinação/flexissegurança, por tratar-se de meros paliativos que não atacam as causas que desencadeiam as patologias sociais, mas procuram transferir para a classe trabalhadora a responsabilidade pelos males que atingem a Sociedade do Trabalho e que, no fundo, tentam legitimar as barbáries contemporâneas.

Para enquadrar aquelas alternativas como possibilidades que conduzem à transferência de responsabilidade - do empregador para o empregador - ou para confundi-la embaralhá-la, deixa-se a observação de Ricardo Antunes dizer:

O que caracteriza o trabalho independente é que: a) trabalha por sua conta; b) suporta os riscos da conta da exploração; c) é responsável, diante de justiça, pelas ações puníveis que possam ocorrer; d) paga suas próprias contribuições sociais, os impostos sobre a renda e sobre a mais valia...; e) contrata seus trabalhadores, se os tem; f) trabalha como independente ("free-lance") para outro empregador, como subcontratado ou como assessor, como consultor, ou como intermediário. Atualmente, no Reino Unido, assistimos um crescimento regular da mão-de-obra independente (ANTUNES, 2009, p. 47).

\subsection{O EMBARALHAMENTO CATEGORIAL SOBRE A SUBORDINAÇÃO E AS NOVAS TECNOLOGIAS DA INFORMAÇÃO E DA COMUNICAÇÃO.}

Antes, no Chão da Fábrica, os modelos organizacionais de cunho gerencialista deixavam transparecer os critérios e as possibilidades de controle do empregador sobre o trabalho do empregado. As formas de vigilância, mesmo para aqueles que prestavam serviços fora da empresa ou em domicílio, eram estabelecidas de modo objetivo, palpável, identificável, por meio de um chefe, de um encarregado, de um supervisor ou, quando mais agressiva, de um capataz.

De uma hora para outra, todo esse critério se dissolveu no ar e em dois sentidos: a) o primeiro refere-se a um controle diuturno que se dá em tempo real e sem a necessidade de uma presença física. Agora, pode-se filmar o ambiente de trabalho, seu entorno e mesmo quando ele é transferido para a própria residência do empregado; a vida privada pode ser fiscalizada e invadida durante as vinte quatro horas do dia; b) em nome 
de uma falsa liberdade ou contraponto à concepção fordista/taylorista, fala-se, agora, em liberdade, quando, na verdade, o controle, forjado nos laboratórios das grandes fundações responsáveis pela elaboração das novas teorias das organizações, se transforma em autocontrole - uma autodisciplina e uma vigilância a ser instituída pelos próprios trabalhadores.

Segundo a socióloga Silva Viana, um controle brutal (2012) assemelhado àqueles instituídos nos chamados reality shows. Numa entrevista concedida a Revista Le Monde Diplomatique (2012), procura demonstrar a face perversa desses relacionamentos destrutivos,

em que o mal é estimulado como parte de um trabalho, uma função como outra qualquer, cujos efeitos colaterais - em especial a dor de fazer mal aos outros - são minimizados mediante a própria justificativa: "Eu só estou cumprindo minha tarefa". Nos patamares acima do chão da fábrica, a lógica não é diferente (Ibidem, p. 6).

Logo, os sentidos da subordinação encontram-se ainda mais presentes e afetam diretamente os trabalhadores do conhecimento, embora eles, envolvidos e capturados pela ideologia organizacional dominante, se vangloriem por estarem exercendo um trabalho descontraído, sem formalismos. Mas, no fundo, trabalham muito mais. Conforme se verá mais adiante, por meio da captura de sua subjetividade, vendem inclusive não só a força de trabalho repetitiva, mas o seu próprio talento, a sua criatividade, o seu saber, a sua alma.

\section{4.“AS ALÇAS DA COOPTAÇÃO" E OS "NOVOS DISPOSITIVOS DE OPRESSÃO” NO CENÁRIO DO NOVO ESPÍRITO DO CAPITALISMO. A VISÃO DE BOLTANSKI E CHAPELLO.}

Os aludidos autores procuram demonstrar que um novo espírito do capitalismo começa a formar-se das entranhas da revolução de 1968, para estabelecer uma inversão de perspectivas: aproveitar-se daquela revolução para, ao enaltecer a crítica estética/artística, esconder a crítica social.

Uma revolução cultural que, embora tenha sido questionada pela versão marxista, sobretudo, o marxismo ortodoxo, foi capaz colocar em relevo e simultaneamente duas 
críticas: a crítica social e a crítica artística/estética. Não foi por acaso que conseguiu reunir operários, estudantes, intelectuais e artistas de vários matizes.

Admitem os referidos autores que o espírito do capitalismo sempre viveu sob a égide do discurso da libertação. Na sua primeira forma, "ganha sentido essencialmente da oposição entre as 'sociedades tradicionais', definidas como opressivas, e as ‘sociedades modernas', únicas capazes de possibilitar autorrealização individual” (Idem, p. 423). Encontra-se aí uma oposição ideológica constitutiva da própria modernidade. Daí o espírito do capitalismo foi conduzido a oferecer, para suas formulações posteriores, "uma perspectiva de libertação capaz de integrar também as críticas que denunciavam a opressão capitalista, ou seja, a não realização de fato das promessas de libertação sob o regime do capital" (Idem, p. 424).

Logo, na versão que interessa a este trabalho, a segunda, em vez do tradicionalismo, ela se concentra na crítica do próprio capitalismo ou naquilo que ele teria instituído de opressivo em suas realizações anteriores. De acordo ainda com os aludidos autores,

O capitalismo coopta, pela instauração de novas modalidades de controle, a autonomia consentida; mas essas novas formas de opressão revelam-se progressivamente e toram-se alvo de crítica, de tal modo que o capitalismo é levado a transformar seus modos de funcionamento para oferecer uma libertação redefinida sob os golpes do trabalho crítico. Mas a 'libertação' assim obtida encerra, por sua vez, novos dispositivos opressivos que, no contexto do capitalismo, possibilitam um novo controle do processo de acumulação. As alças da cooptação, portanto, criam uma sucessão de períodos de libertação pelo capitalismo e de libertação do capitalismo. (Idem, p. 424).

Este espírito do capitalismo apresenta, contraditoriamente, uma autorrealização imposta e novas formas de opressão. Cooptar a autonomia, exigir grandezas decorrentes de sua capacidade de autorrealização passam a se constituir como critérios para avaliação dos trabalhadores.

No momento em que passa a se apropriar da crítica estética, para esconder a crítica social, o novo espírito do capitalismo deixa, como consequência, que

O aumento da autonomia e da responsabilidade ocorreu à custa da diminuição das proteções de que os assalariados gozavam no início do período, proteções que resultavam não só da conjuntura econômica, mas também do equilíbrio de poder que lhes fora temporariamente favorável. Conforme tivemos ocasião de mostrar 
no capítulo III. A autonomia foi obtida em troca das garantias, de tal modo que se trata frequentemente de uma autonomia imposta, não escolhida, dificilmente sinônimo de liberdade: 'os assalariados recém transformados em empreendedores' continuam a depender do empregador principal, e a subordinação é apenas dissimulada formalmente pela passagem do "direito do trabalho' para o 'direito comercial” (Idem, p. 430).

\section{OS EFEITOS DA RECONFIGURAÇÃO DO PODER DIRETIVO E DA SUBORDINAÇÃO NO ÂMBIDO DOS TRABALHADORES DA TECONOLGIA DA INFORMAÇÃO E DA CUMUNICAÇÃO.}

A complexidade do tema que envolve informação e conhecimento e, dentro dela, os infoproletários, aponta para uma rica bibliografia - nacional e estrangeira -, que seria impossível esgotá-la, nesta oportunidade. ${ }^{13}$ Assim, não se tem aqui a pretensão de descrever todas as variáveis da exploração do trabalho, nesta fase considerada por alguns de organização do trabalho pós-taylorista.

A professora Fernanda Barreto Lira (2015) - a partir de uma versão analítica consistente, de uma narrativa original, impactante; depois de apontar as diversas possibilidades de adoecimento que acontecem fora e dentro das organizações, mas que resultam do trabalho livre/subordinado e sob a pressão deste novo espírito do capitalismo - chega a seguinte conclusão: as relações de trabalho, tal como foi concebida pela sociedade moderna e recepcionada pelo Direito do Trabalho, são relações de poder. ${ }^{14}$

Assevera Ricardo Antunes (2011) que o livro Infoproletários

Busca revelar a face sombria dessa atividade globalizada: a tendência à alienação do trabalho informacional. Ao mesmo tempo, procura inserir esse movimento num quadro mais amplo, explorando a

\footnotetext{
${ }^{13}$ A propósito, ver: MARQUES, Rodrigo Moreno [ET al.]. A Informação e o conhecimento sob as lentes do marxismo. Rio de Janeiro: Garamond, 2014; ANTUNES, Ricardo; BRAGA, Ruy. Infoproletários. Degradação real do trabalho virtual. São Paulo: Boitempo, 2011;

${ }^{14}$ LIRA, Fernanda Barreto. Meio Ambiente do Trabalho e Enfermidades Profissionais: os rituais do sofrimento e a morte lenta no trabalho no contexto do trabalho livre subordinado. Recife: Texto Avulso tese de doutorado. Programa de Pós-graduação em Direito da UFPE, setembro de 2015. Mais dois trabalho devem ser aqui ressaltados posto que abordam especificamente as relações de trabalho nas tecnologias da comunição e da informação: FILHO, Carlo Benito Cosentino. O Trabalho Imaterial e os Trabalhadores do Conhecimento. As novas possibilidades de reinvenção das lutas coletivas. Programa de Pós-graduação em Direito da UFPE.Recife: Dissertação de Mestrado, texto avulso, 2011. O Direito do Trabalho na Revolução Informacional e nas Teorias dos Movimentos Sociais: impactos no postulado autonomia, nas relações individuais e coletivas de trabalho. Recife. PPFD/UFPE, Tese de Doutorado. Texto Avulso, 2017.
} 
multidimensionalidade desse fenômeno por meio da análise dos novos modelos gerenciais, da formação de uma nova condição proletária nos serviços, das características da estrutura sócio-ocupacional desse setor econômico, da recomposição do controle e gestão do trabalho, das novas formas de obtenção de consentimento à exploração econômica, da produção de novas e precárias identidades coletivas, das desigualdades de gênero, das trajetórias profissionais... Infoproletários procura descortinar as formas de ser do cibertariado, para utilizarmos uma feliz caracterização de Ursula Huws - também presente neste volume (Idem, p. 9).

Várias patologias psicofísicas decorrem desta nova morfologia do trabalho e apontam, sobretudo, para de três variáveis: a forma de acesso ao trabalho; a utilização dos aparelhos e equipamentos, aliada ao grau de intensificação e de exposição a esses mesmos mecanismos ou instrumentos de trabalho; à falsa concepção de liberdade, que se traduz, na prática, numa exploração sem precedentes.

Identifique-se, resumidamente, três experiências que são fruto desta nova morfologia. O primeiro, referindo-se ao acesso daqueles profissionais considerados operadores de telemarketing ou de teleatendimento. O constrangimento começa na porta da entrada. De forma subliminar, deixa-se transparecer algo mais ou menos assim: você é feio (a), gordo (a), preto (a), homossexual... Ninguém vai lhe ver mesmo! A sua voz compensa suas "deformações”! Agradeça o emprego que tem e não reclame! Existem outras (os) na mesma situação, esperando um vacilo seu!!!

O segundo, também muitíssimo afetado - em todo o planeta e, sobretudo, nos países que mais se utilizam das novas tecnologias - envolve aqueles considerados como digitadores. É comum serem atingidos por uma enfermidade chamada LER - Lesão Por Esforço Repetitivo.

Por fim, os profissionais que lidam com o processo criativo, que vendem o seu talento, o produto da sua criação artística, cultural, tecnológica ou científica. Seriam aqueles que exercitam os chamados trabalhos criativos, como chama Maria Ptqk. O mais grave, nesta esfera, é que esses trabalhadores gostam do que fazem e por isso o fazem a qualquer preço.

Daí, ao contrário do quem diz o marketing empresarial e a teoria organizacional conservadora - que se espalham e impregnam todos os meios de comunicação - afirma referida autora: 
Pero ¿cuáles son realmente las características de esta nueva forma de trabajo? En su análisis sobre las condiciones laborales en la industria del new media, Rosalind Gill identifica un repertorio de estímulos: el placer y la diversión; la autonomía, el emprendizaje y la ausencia de jerarquías; la innovación y el aprendizaje permanente; la comunicación y el intercambio; la posibilidad de participar en proyectos de impacto social; la percepción de que estos entornos de trabajo son igualitarios y abiertos a la diversidad; y la fascinación por lo novedoso del sector. En su "Pentagram of Creative Work" Zoe Romano10 señala un elemento más: el prestigio y el reconocimiento entre pares. Ambas investigaciones destacan que los creativos están profundamente convencidos de que lo que hacen es beneficioso para el conjunto de la sociedad y que casi todos viven su profesión como un espacio idóneo para la acción social. También coinciden en que, entre sus motivaciones, la dimensión económica y la seguridad laboral son elementos secundarios: "Si quisiera tener un empleo estable y ganar dinero me dedicaría a otra cosa" dice uno de los entrevistados por Gill. El resultado es que para los creativos, los límites entre los tiempos/espacios de vida y los de trabajo se diluyen. Han conseguido transformar sus aficiones en una profesión y perciben esto como una ventaja, incluso como una victoria contra el trabajo convencional y todo lo que este representa de alienación y servidumbre. "Es como si te pagaran por dedicarte a tu hobby. ${ }^{15}$

O fato é que se está vivenciando um boom da tecnologia cada vez mais presente na vida das pessoas. Elas se tornam reféns dessas mesmas tecnologias. O mundo chamado de pós-industrial tem sido palco de grandes acontecimentos que, até pouco tempo, eram inimagináveis. Em apenas 20 anos, a internet se tornou indispensável, o telefone se tornou popular, capacidades dos computadores se ampliaram, sem que seja possível imaginar as suas infinitas potencialidades - quando, antigamente, eram gigantescos e completamente inacessíveis às grandes massas; as máquinas inteligentes e a robótica substituem o trabalho braçal.

Com o aparecimento dessas novas tecnologias, surgiram também novas profissões e, com elas, uma metamorfose sem precedentes que aponta, de um lado, para relações de

15 PTQK, Maria. Be creative under-class! Mitos, paradojas y estrategias de la economía del talento. disponível em $\quad<\quad$ http://www.laciudadviva.org/blogs/wpcontent/uploads/2009/08/be creative underclass_maria_ptqk2.pdf $>$, acesso no dia 29 de agosto de 2013. Ressalte-se também que, segundo, PRIMI, Lilian, ficam eles, conforme o titulo: Ligados 24 horas. Pressão de estar on-line acarreta patologias sociais e muda perfil de doenças do trabalho. Revista Caros amigos, São Paulo, Julho 2013. 
trabalho ainda mais complexas e multifacetadas; do outro, para uma avassaladora precarização, que passou a conviver com o chamado desemprego estrutural. ${ }^{16}$

Acontece que, no campo da tecnologia da informação e comunicação, existe, como já ficou evidenciado, uma exploração ainda maior. Além de não se identificar rupturas, no âmbito do tema objeto deste artigo - a subordinação e o poder punitivo do empregador -, houve um falseamento dos mesmos, a partir da introdução de um conceito enganoso de liberdade no trabalho - empregado agora é chamado de "colaborador", "associado", "parceiro", “empreendedor'. Por outro lado e em nome dessas metamorfoses, a prorrogação da jornada de trabalho foi ampliada. Os trabalhadores ficam, sob o manto da liberdade criativa, ainda mais subordinados e submetidos a jornadas ainda mais alongadas. ${ }^{17}$

\section{CONCLUSÃO}

O Direito do Trabalho se tornou um campo específico do conhecimento jurídico, na medida em que elegeu, como seu objeto, o trabalho contraditoriamente livre/subordinado. Por meio deste objeto, foi capaz de construir seus fundamentos, seu corpo de doutrinas, um arcabouço legislativo e uma autonomia didática que tinham como finalidade eliminar a assimetria presente num determinada relação jurídico-trabalhista centrada na subordinação ou no poder punitivo ou disciplinar do empregador.

Todos os esforços desenvolvidos pela doutrina tradicional - parassubordinação, flexissegurança -, não foram capazes de superar aquela contradição. Ao contrário, ela se acentua e se revela ainda mais poderosa quando articulada com as proposições lançadas pela teoria organizacional conservadora - empregabilidade, empreendedorismo.

\footnotetext{
${ }^{16}$ Para se ter uma ideia do quão recente é essa área aqui, em Pernambuco, o Centro de informática da UFPE foi criado em 1999 e o curso de graduação em ciência da computação, em 1975. O curso de engenharia da computação, apenas em 2002 e o de sistema da informação, ainda mais recente, em 2010.

${ }^{17}$ Boltansky e Chiapello afirmam que o Novo Espírito do Capitalismo capturou, da Revolução empreendida em 1968, a crítica estética, para esconder e reprimir a crítica social. Por esse viés é possível identificar os sentidos falseados das "liberdades" que aparecem nas propagandas, nos estilos de vida e, no trabalho, por meio do discurso dirigido à Empregabilidade e ao Empreendedorismo. BOLTAN SKI, Luc; CHIAPELLO, Ève. O Novo Espírito do Capitalismo. São Paulo: Editora WMF: Martins Fontes, 2009.
} 
Este trabalho procurou evidenciar que o aparecimento das novas tecnologias da informação e da comunicação, ao recepcionar uma autorrealização imposta, passou a cooptar a autonomia, a capturar a subjetividade e a alma dos trabalhadores e impor novas formas de opressão no interior das organizações que o Direito do Trabalho não pode desconhecer.

Neste contexto, procurou revelar também a face sombria que envolve a alienação do trabalho informacional, que tira partido da multidimensionalidade desse fenômeno e recompõe o controle e a gestão do trabalho, para adquirir novas formas de obtenção de consentimento e de exploração.

Logo, só haverá libertação, por meio do trabalho, quando for eliminado o pressuposto subordinação da força do trabalho ao capital, ou melhor: O Modo de Produção Capitalista, quer subordina a força de trabalho ao capital. .

Enquanto esta reviravolta não acontecer, é possível falar-se em reconfiguração teórico-dogmática do Direito do Trabalho, a partir de uma drástica redução da jornada de trabalho, da prevalência da Economia Solidária e da adoção de uma Renda Universal Garantida $^{18}$, como propõem alguns autores que integram um novo corpo de doutrinas vinculado à teoria jurídico-trabalhista crítica.

\section{REFERÊCIAS}

ANDRADE, Everaldo Gaspar Lopes de Andrade. Direito do Trabalho e Pósmodernidade. Fundamentos para uma teoria geral. São Paulo: Ltr, 2005.

Fundamentos Teórico-filosóficos. São Paulo: LTr, 2008.

. Princípios de Direito do Trabalho. O Direito do Trabalho na Filosofia e na Teoria Social Crítica. Os sentidos do trabalho subordinado na cultura e no poder das organizações. São Paulo: LTR, 2014.

ANTUNES, Ricardo. BRAGA, Ruy (org.). Infoproletários: degradação real do trabalho virtual. São Paulo: Boitempo, 2009.

${ }^{18}$ ESTEVES, Juliana Teixeira. O Direito da Seguridade Social e da Previdência Social. A Renda Universal Garantida. A taxação dos fluxos financeiros internacionais e nova proteção social. Recife: Editora UFPE, 2015. 
BERNARDI (BIFO), Franco. A fábrica da infelicidade: trabalho cognitivo e crise da new economy. Rio de Janeiro: DP\&A, 2005.

BEZERRA, Zélia Costa Santos. A Subordinação no Direito do Trabalho: as implicações da tecnologia da informação e da comunicação na reconfiguração deste instituto. Recife: PPGD/UFPE, Dissertação de Mestrado, Texto /avulso, 2015

BOltanski, Luc; CHIAPEllo, Ève. O Novo Espírito do Capitalismo. São Paulo: Editora WMF: Martins Fontes, 2009.

COCCO, Giuseppe; GALVÃO, Alexander Patez; SILVA, Geraldo (orgs.) Capitalismo cognitivo: trabalho, redes e inovação. Rio de Janeiro: DP\&A, 2003.

COUTINHO, Aldacy Rachid. O Poder Punitivo Trabalhista. São Paulo: LTr, 1999.

FILHO, Carlo Benito Cosentino. O Trabalho Imaterial e os Trabalhadores do Conhecimento. As novas possibilidades de reinvenção das lutas coletivas. Programa de Pós-graduação em Direito da UFPE.Recife: Dissertação de Mestrado, texto avulso, 2011. O Direito do Trabalho na Revolução Informacional e nas

Teorias dos Movimentos Sociais: impactos no postulado autonomia, nas relações individuais e coletivas de trabalho. Recife. PPFD/UFPE, Tese de Doutorado. Texto Avulso, 2017.

D’ANGELO, Isabele de Moraes. A Subordinação no Direito do Trabalho. São Paulo: LTr, 2014.

DELAGADO, Maurício Godinho. O Poder Empregatício. São Paulo: LTR, 1996 GORZ, André. Crítica da divisão do trabalho. 3. Ed. São Paulo: Martins Fontes, 1996. Metamorfoses do trabalho: crítica da razão econômica. 2. Ed. São Paulo: Annablume, 2007.

ESTEVES, Juliana Teixeira. O Direito da Seguridade Social e da Previdência Social. A Renda Universal Garantida. A taxação dos fluxos financeiros internacionais e nova proteção social. Recife: Editora UFPE, 2015.

O imaterial: conhecimento, valor e capital. São Paulo: Annablume, 2005.

LAZZARATO, Maurizio; NEGRI, Antônio. Trabalho imaterial: formas de vida e produção da subjetividade. Rio de Janeiro: DP\&A, 2001.

LESSA, Sérgio. Para além de Marx? Crítica da teoria do trabalho imaterial. São Paulo: Labirintos do trabalho, 2005.

LIRA, Fernanda Barreto. Meio Ambiente do Trabalho e Enfermidades Profissionais: os rituais do sofrimento e a morte lenta no trabalho no contexto do trabalho livre subordinado. Recife: PPGD/UFPE, tese de doutorado, texto avulso, 2015. 
LOJKINE, Jean. Revolução Informacional. 3.ed. Cortez Editora: São Paulo, 2002.

MARQUES, Rodrigo Moreno [et al] A informação e o conhecimento sob as lentes do marxismo. Rio de Janeiro: Garamond, 2014.

MELHADO, Reginaldo. Poder e Sujeição. Os fundamentos da relação de poder entre capital e trabalho e o conceito de subordinação. São Paulo: LTR, 2003.

PRIMI, Lilian. Ligados 24 horas. Pressão de estar on-line acarreta patologias sociais e muda perfil de doenças do trabalho. Revista Caros amigos. São Paulo, Julho 2013.

PTQK, Maria. Be creative under-class! Mitos, paradojas y estrategias de la economía del talento. Disponível em $<$ http://www.laciudadviva.org/blogs/wpcontent/uploads/2009/08/be creative underclass maria ptqk2.pdf $>$. Acesso no dia 29 de agosto de 2013

RIVAS, Daniel. La Subordinación. Criterio distintivo del contrato de trabajo. Montevideo: Fundación Cultura Universitária, 1996;

ROMITA, Arion Sayão Romita. A Subordinação no Contrato de Trabalho. Rio de Janeiro: Forense, 1979

SHAFF, Adam. A sociedade informática: as consequências sociais da segunda revolução industrial. 4. Ed. São Paulo: Editora da Universidade Estadual Paulista: brasiliense, 1995.

TRIVINHO, Eugênio. A democracia cibercultural: lógica da vida humana na civilização mediática avançada. São Paulo: paulus, 2007.

VALENCIA, Adrian Sotelo. A estruturação do mundo do trabalho: superexploração e novos paradigmas da organização do trabalho. Uberlândia: EDUFU, 2009. 